\title{
ESPAÇO E SOCIEDADE EM PIRAPOZINHHO - SP: DISCUSSÕES FUNDAMENTADAS NAS PERCEPÇÕES DE JANE JACOBS
}

Bruna Fagliari Sposito, Giovana Peruchi Simões, Graziely Ribeiro Hippler, Mayara Pissutti Albano

Universidade do Oeste Paulista - UNOESTE. Curso de Arquitetura e Urbanismo, Presidente Prudente - SP.

\section{RESUMO}

Conhecer as características de uma cidade e sua população é de grande importância para o desenvolvimento de um planejamento urbano que seja munido de instrumentos de gestão condizentes com os hábitos e culturas do local a se intervir, e assim, seja um planejamento de fato efetivo; O presente trabalho apresenta uma análise da estrutura sócioespacial urbana de Pirapozinho, cidade de pequeno porte do interior do estado de São Paulo, fundada nas primeiras décadas do século XX. As análises foram desenvolvidas baseadas nos levantamentos bibliográficos realizados, enfatizando as percepções, sobre tais estruturas, da autora Jane Jacobs, que possui uma visão muito particular sobre a dinâmica socioespacial urbana, e de levantamentos de campo, a partir da observação direta.

Palavras-chave: Planejamento urbano, Vitalidade urbana, Espaço público, Pirapozinho - SP .

\section{SPACE AND SOCIETY IN PIRAPOZINHHO - SP: ARGUMENTS BASED ON PERCEPTIONS OF JANE JACOBS}

\begin{abstract}
Know the characteristics of a city and its population is of great importance for the development of an urban planning that is provided with management tools consistent with local cultures and habits to intervene, and thus be an effective planning of fact; This study presents an analysis of urban sociospatial structure of Pirapozinho, small town in the state of São Paulo, founded in the early decades of the twentieth century. The analyzes were developed based on literature surveys conducted, emphasizing perceptions on such structures, by Jane Jacobs, who has a very particular vision of urban socio-spatial dynamics, and field surveys, the direct observation.

Keywords: Urban Planning, Urban Vitality, Public space, Pirapozinho - SP .
\end{abstract}




\section{INTRODUÇÃO}

A cidade pode ser considerada um organismo vivo, pois está em constante movimento. São muitas atividades e mutações ocorrendo simultaneamente: pessoas e carros circulando, reformas acontecendo, bairros novos surgindo. Ela não para. No entanto, não existe a cidade perfeita, todas possuem problemas, em escalas diferentes, mas que não devem ser deixados de lado. Para se entender os problemas sociais que o meio urbano acarreta como a violência e a falta de segurança nas ruas, deve-se analisar os mecanismos da cidade, como ela se desenvolve e se organiza.

O presente artigo objetiva discutir e analisar o espaço urbano da cidade de Pirapozinho - SP segundo Jacobs (2007), que traz em seu discurso questões relacionadas ao uso do espaço urbano, sua configuração e as características socioespaciais, que são comuns em diversas cidades, buscando trazer tais discussões para a realidade da cidade citada, cidade localizada do interior paulista.

Analisar e discutir o espaço intra-urbano (VILLAÇA, 1998) nas cidades brasileiras são importantes referenciais para compreensão dos processos que nelas ocorrem. Reconhecer a realidade de uma cidade proporciona informações importantes ao planejamento, visto que é um meio de juntar subsídios que venham contribuir para a qualidade de vida da população, passando a existir a necessidade de diagnóstico da existência ou não de condições habitação e vivência, em termos sociais, ambientais, econômicos, entre outros (ALBANO,2013).

Jacobs $(2007$, p.1 - 2) ratifica a importância de se conhecer "[...] o funcionamento das cidades na prática, porque essa é a única maneira de saber que princípios de planejamento que iniciativas de reurbanização conseguem promover a vitalidade socioeconômica nas cidades e quais práticas e princípios a inviabilizam".Assim têm-se a dimensão da importância de levantamentos e análises urbanas como as apresentadas a seguir.

\section{METODOLOGIA}

A metodologia seguida foi baseada em levantamentos bibliográficos, buscando compreender os conceitos relativos ao tema abordado e a formulação de uma avaliação lógica da problemática. Em seguida foram realizados levantamento de campo através da observação intensiva.

\section{ANÁLISES URBANAS DA CIDADE DE PIRAPOZINHO - SP}

Emancipada em 9 de abril de 1949, Pirapozinho está localizada na região oeste do estado de São Paulo, à 574 km da capital, com uma população de 24.694 habitantes (IBGE, 2010). A 
cidade possui intensa atividade comercial, que gera grande movimentação na área central da cidade. Em áreas mais afastadas, também há indústrias, fazendo parte da atividade econômica do município, como a Braswey S/A, atuante no ramo de óleos vegetais.

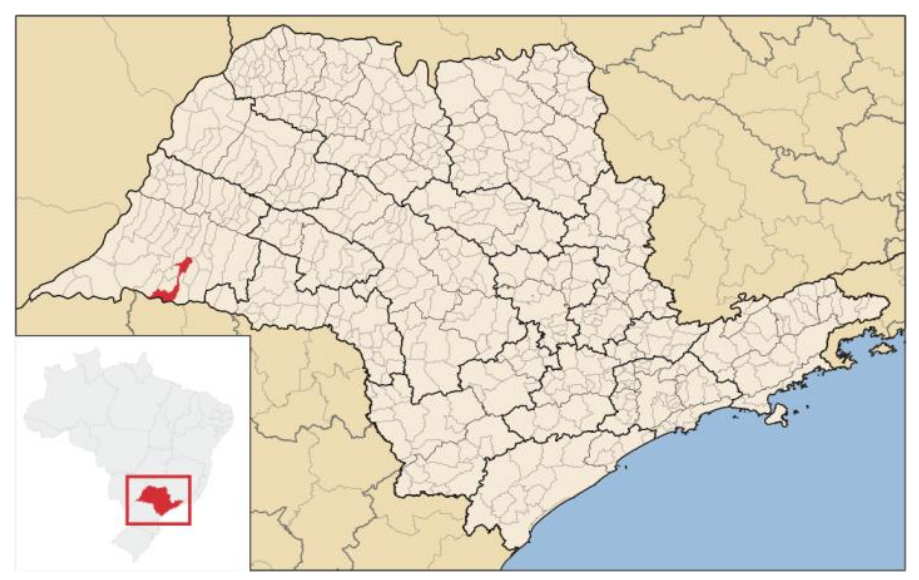

Figura 1. Localização de Pirapozinho - SP.

Fonte: http://pt.wikipedia.org

Segundo o website oficial do município, Pirapozinho era um lugarejo ligado à Presidente Prudente por uma trilha aberta no meio da mata densa. No ano de 1933, um engenheiro da Prefeitura Municipal de Presidente Prudente, traçou a planta de loteamento dos terrenos, que logo começou a ser habitado. Como o local oferecia boa passagem para os sitiantes da região, que seguiam à Presidente Prudente, foi acelerada sua colonização, o desenvolvimento do comércio e a conseqüente formação de propriedades agrícolas nas imediações, propriedades estas que constituem a principal estrutura econômica do município. As famílias foram se agrupando em torno da atividade comercial e agrícola, atraindo para o local notáveis melhoramentos. A cidade era composta por cinco distritos, Itororó do Paranapanema, Estrela do Norte, Tarabai, Sandovalina e Narandiba, que se desmembraram-se em cidades na década de 50, permanecendo apenas o primeiro.

\section{O USO DOS ESPAÇOS PÚBLICOS URBANOS}

O espaço público, segundo Borja (2003), é um espaço utilizado como lugar de representação e de expressão coletiva da sociedade; espaços que geram, amparam, e tornam mais fácil as relações sociais, bem como as culturais em uma cidade (CARMONA, et al,2003 appud BALLULA, 2010). Para Gehl (2013, p. 22) "Atividades sociais exigem a presença de outras pessoas e incluem todas as formas de comunicação entre as pessoas no espaço público". 
A segurança nas cidades é primordial para o bem estar público. "E, quando temem as ruas, as pessoas as usam menos, o que torna as ruas ainda mais inseguras." (JACOBS, p.30) O uso das áreas urbanas, ou seja, a presença constante de pessoas, torna os espaços públicos mais cheios de vida e seguros. O centro de Pirapozinho, observado durante a pesquisa, é muito movimentado durante o dia devido à atividades comerciais; porém durante o período noturno, como seu movimento diminui significativamente, está mais propício è periculosidade. Neste caso a iluminação pública presente, e em bom estado, se torna muito importante. Na referida cidade, somente as áreas que fazem o limite entre a zona urbana e a zona rural são mais escuras e desprotegidas.

Um ponto favorável na cidade, que evita que o centro fique sem qualquer movimento durante a noite, são suas avenidas, que praticamente "cortam" Pirapozinho ao meio (Figura 2), quando se interligam entre as duas principais entradas da cidade, elas se tornam caminhos comuns para qualquer deslocamento dentro da cidade, mantendo um certo movimento de automóveis, mas que não substitui a presença de pessoas.

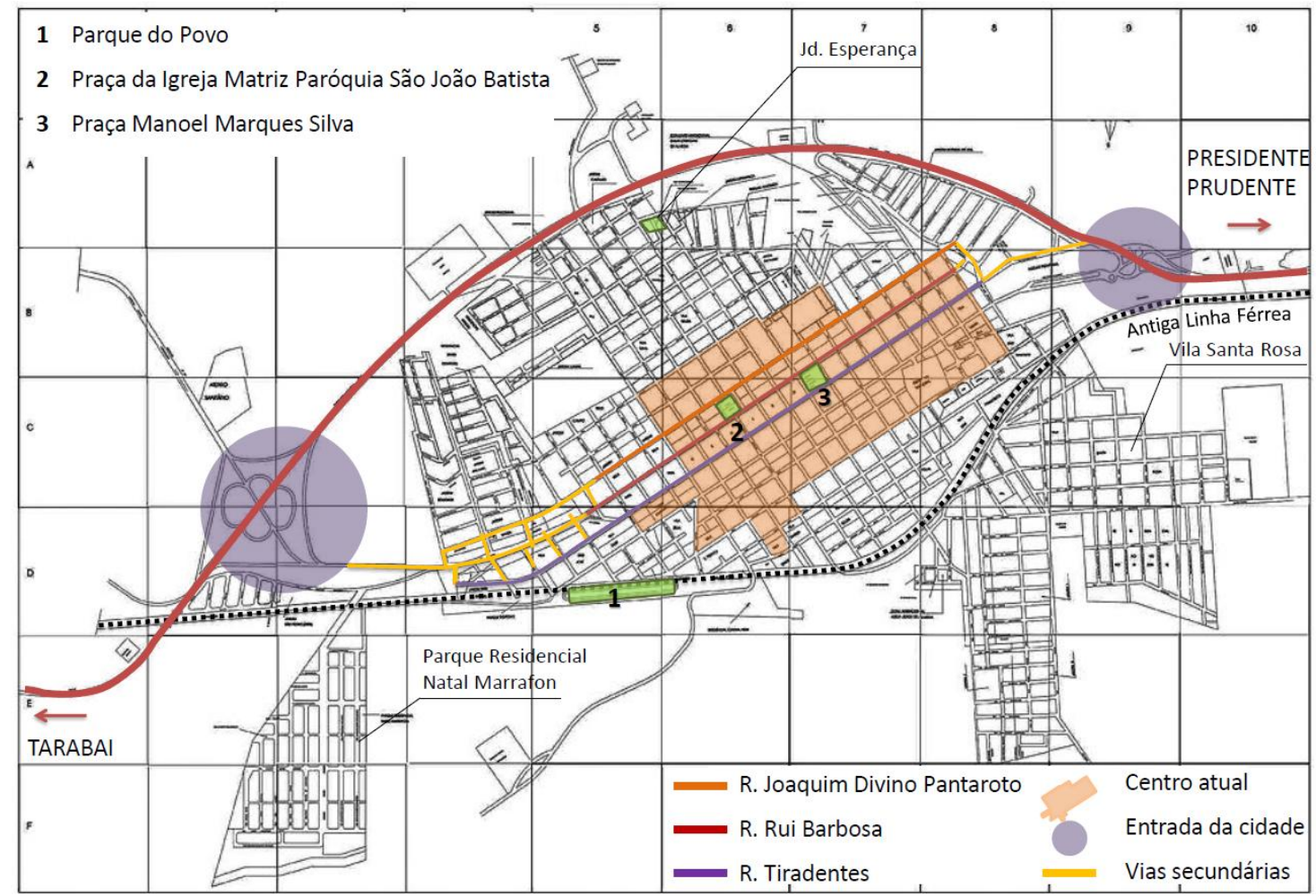

Figura 2. Mapa da cidade, principais vias e áreas verdes Fonte: Autoras, 2014.

Um local que é evitado pela população, em determinado horário, é o Parque do Povo. Durante o dia, as pistas de caminhada estão em constante uso, porém depois do anoitecer, por 
volta das 20 horas, o "deserto" toma conta. A pouca iluminação e a presença de usuários de drogas, motivam as pessoas à não usufruírem do local.

As ruas certamente são o palco das brincadeiras das crianças na cidade principalmente nos bairros de baixa renda. Os espaços públicos passam a ser uma espécie de local da diversão, fato favorável à vitalidade urbana segundo Jacobs (2007). Motivo este, provocado pela falta de espaços para atividades, como playgrounds.

Não existem em Pirapozinho muitos exemplares de áreas públicas como praças, parques infantis, ou mesmo locais destinados ao lazer e promoção de convívios sociais. Há somente três áreas importantes, que estão em uso, que são o Parque do Povo, e as praças Padre Hilário Pierick, da Igreja Matriz São João Batista e a Praça Manoel Marques Silva, ambas no centro (ver Figura 1). Há também outros espaços púbicos destinados ao lazer, porém possuem somente vegetação e alguns bancos, mas não oferecem atrativos à opulação.
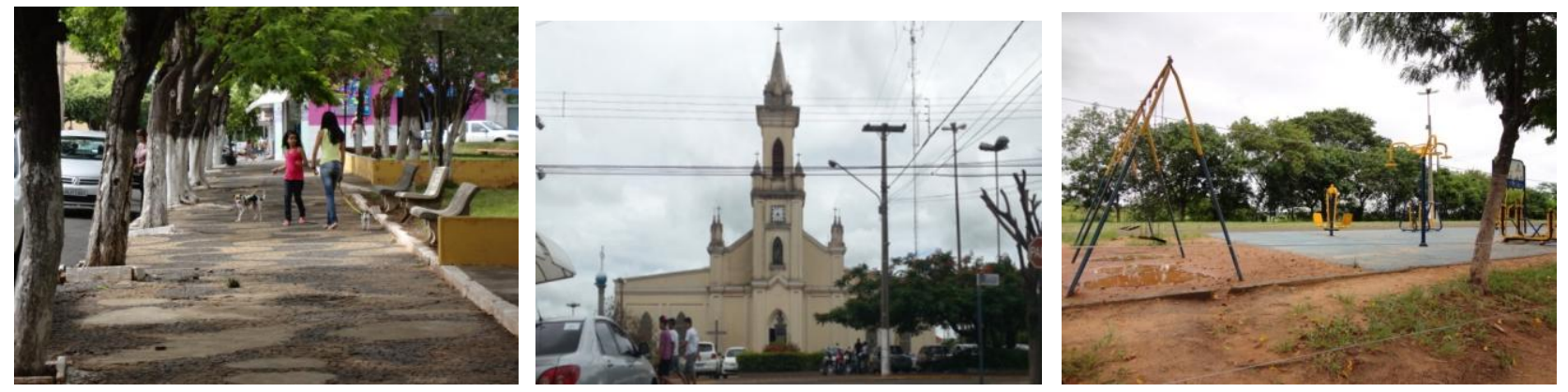

Figura 3. Praça Manoel Marques Silva , Praça da Igreja e Parque do Povo Fonte: Autoras, 2014.

A Praça Manoel Marques Silva está inserida em um terreno com acentuado aclive, e seus planos em níveis diferentes fazem com que a pessoa tenha vários pontos de vistas diferentes. É a praça mais movimentada, em função dos atrativos que oferece, como planos diferentes que a compõe, pois conforme afirma Jacobs (2007,p.112 - 113) "Parques muito usados [...] costumam incluir em seu projeto [...] complexidade visual, mudanças de nível no piso, agrupamentos de árvores, espaços que abrem perspectivas variadas". A praça também possui uma grande movimentação devida á variedade de estabelecimentos em seu entorno, o que aumenta o tempo em que as pessoas possam utilizá-la.

Durante o dia, a movimentação se dá pelos alunos da escola, que fica em frente a praça, também por pessoas à caminho do trabalho e por idosos que encontram seus amigos para jogarem. À noite, ela se torna ponto de embarque para os estudantes de Pirapozinho que se 
dirigem à faculdades da região. Também é requentada por pessoas que vão à sorveteria e à pastelaria logo em frente. Mantendo-se cheia de vitalidade e bastante utilizada até às 22 horas.

A Praça Padre Hilário Pierick, conhecida popularmente como praça da igreja, pois é onde se encontra a Igreja Matriz Paróquia São João Batista, perdeu um pouco de sua função de área pública de lazer quando passou a ser utilizada como estacionamento durante o dia, principalmente em dias de missa, limitando o espaço que poderia ser utilizado pela população e que Ihe traria vitalidade. Gehl (2013, p. 17), afirma que "[...] se oferecido um melhor espaço urbano o uso irá aumentar [...]", fato que não ocorre na referida praça.

O Parque do Povo trata-se de um parque inserido na antiga área dos trilhos da ferrovia. 0 local passou por um processo de revitalização, e como resultado o parque é composto por um pequeno parquinho e pista para caminhada, é o espaço utilizado para eventos da cidade como a FEJUP, festa junina tradicional, conhecida em toda região.

Jacobs (2007), também discorre sobre o tamanho das quadras de um bairro para que sejam de melhor eficiência aos seus moradores. As quadras curtas, ou seja, aquelas que apresentam pequena extensão para uma pessoa "dobrar à esquina" são as que levam maior vantagem. As pessoas adquirem maior espírito de vizinhança, visto que acabam por conhecer melhor sua quadra, já que permitem trajetos mais curtos e variados, sendo mais acessíveis, contribuem para as atividades comerciais.

Em Pirapozinho, as quadras curtas aparecem na maior parte da malha urbana, principalmente na parte mais antiga da cidade, onde está o centro hoje e alguns bairros que o contorna. Porém, com o desenvolvimento da cidade e seu crescimento, devido ao mercado imobiliário (menos ruas, mais lotes, mais capital) as quadras tem se tornado mais longas. Um exemplo de quadras longas é o Conjunto Habitacional Antônio Bento Pimentel, que atualmente é composto apenas por residências e que está em pleno desenvolvimento.

Para Jacobs (2007, p. 123) “Um bairro bem sucedido é aquele que se mantém razoavelmente em dia com seus problemas, de modo que eles não o destruam. Um bairro mal sucedido é aquele que se encontra sobrecarregado de deficiências e problemas e cada vez mais inerte diante deles."

Em bairros onde moram pessoas de classes sociais mais altas, em geral, possuem melhor infraestrutura. Um exemplo visto na cidade de Pirapozinho é o centro, bairro de classe média alta, que possui boa infaestrutura, bem como o bairro Morada do Sol. No entanto, o fator determinante para a vitalidade em um bairro é a diversidade, conseguida principalmente através da diversidade dos usos. Jacobs (2007) discorre que as moradias devem ser complementadas por 
outros usos principais, como trabalho e diversão, para assim promover um uso intenso do solo urbano a fim de contribuir efetivamente para a concentração populacional. "Sem dúvida, as moradias [...] devem ser complementadas por outros usos, principais, de modo que haja uma boa distribuição de pessoas nas ruas em todas as horas do dia". (JACOBS, p.222)

A densidade habitacional (quantidade de moradias por área) de Pirapozinho é praticamente a mesma em todos os bairros antigos residenciais, por possuir o mesmo tamanho de lotes. E estes se misturam com alguns comércios de bairro. Se tornando bairros de boa diversidade urbana. No entanto, há os bairros também com alta concentração de densidade habitacional, como o Conjunto Habitacional Antônio Bento Pimentel, que possui lotes pequenos, quadras compridas, sem estabelecimentos comerciais e com pouca estrutura, portanto não possui diversidade urbana.

\section{CONSIDERAÇÕES FINAIS}

Fazendo, portanto os levantamentos destas abordagens, nas quais várias apresentaram problemáticas, foi possível identificar irregularidades e qualidades urbanísticas que influenciam diretamente o meio social. Algumas tão visíveis, como furtos no centro da cidade decorrente do mal uso noturno, quanto outros, mais discretos, em bairros que aparentam inseguros pela falta de movimento nas ruas causado pelos próprios moradores que não possuem o espírito de vizinhança e ali se fecham . São análises que poderão gerar um futuro projeto de intervenção e planejamento urbano, a fim de melhorar a cidade e os problemas da sociedade.

\section{REFERÊNCIAS}

ALBANO, Mayara Pissutti. A Importância do Planejamento Urbano Ambiental - A Habitação Social e a Expansão Urbana em Presidente Prudente - SP. 2013. Dissertação (Mestrado) Universidade do Oeste Paulista,Presidente Prudente.

BALULA, Luís. Espaço Público e a Criatividade Urbana. A dinâmica dos logares em três bairros culturais. Cidades - Comunidades e Territórios. Dez 2010. N²0/21, pp 43-58.

BORJA, Jordi, e MUXI, Zaida. El Espacio Público, Ciudad e Cidadania, Electa, 2003.

GEHL, Jan. Cidade Para Pessoas; tracução Anita Di Marco - 1 ed. - São Paulo: Perspectva, 2013.

IBGE, Instituto Brasileiro de Geografia e Estatística, 2010. Disponível em: http://www.ibge.gov.br/. Acesso em 12 de março de 2014.

JACOBS, Jane. Morte e Vida de Grandes Cidades. 2a Edição. São Paulo: Martins Fontes, 2009. 
PIRAPOZINHO - SP Website oficial do município. Disponível em: http://www.pirapozinho.sp.gov.br/. Acesso em: 13 de março de 2014.

VILLAÇA, F. Espaço Intra-urbano no Brasil. São Paulo: Studio Nobel: FAPESP: Lincoln Institute, 2001. 373p. 